\title{
Determinants of neonatal mortality in rural India, 2007-08
}

Background: Despite the growing share of neonatal mortality in Under-5 mortality in the recent decades in India, most of the studies have focused on infant and child mortality putting the neonatal mortality on the back seat. The development of focused and evidence-based health interventions to prevent neonatal deaths warrants examination of factors affecting it. This study attempted to examine the individual, household, and community level factors affecting neonatal mortality in rural India.

Data and methods: We analysed information on 171,529 singleton live births using the data from the most recent round of the District Level Household Survey conducted in 2007-08. Principal component analysis was used to create an asset index. Two-level logistic regression was performed to analyse the factors associated with neonatal deaths in rural India. Results: The odds of neonatal death were lower for neonates born to mothers with secondary level education ( $\mathrm{OR}=0.60, \mathrm{p}=0.01$ ) compared to those born to illiterate mothers. A progressive reduction in the odds occurred as the level of fathers' education increased. The odds of neonatal death were lower for infants born to unemployed mothers $(\mathrm{OR}=0.89, \mathrm{p}=0.00)$ compared to those who worked as agricultural worker / farmer / laborer The odds decreased if neonates belonged to Scheduled Tribes ( $\mathrm{OR}=0.72, \mathrm{p}=0.00)$ or 'Others' caste group $(\mathrm{OR}=0.87, \mathrm{p}=0.04)$ and to the households with access to improved sanitation ( $\mathrm{OR}=0.87, \mathrm{p}=0.02)$, pucca house ( $\mathrm{OR}=0.87, \mathrm{p}=0.03)$ and electricity $(\mathrm{OR}=0.84, \mathrm{p}=0.00)$. The odds were higher for male infants $(\mathrm{OR}=1.21, \mathrm{p}=0.00)$ and whose mother experienced delivery complications $(\mathrm{OR}=1.20, \mathrm{p}=0.00)$. Infants whose mothers received two tetanus toxoid injections ( $\mathrm{OR}=0.65, \mathrm{p}=0.00)$ were less likely to die in the neonatal period. Children of higher birth order were less likely to die compared to first birth order. Conclusion: Ensuring the consumption of an adequate quantity of Tenatnus Toxoid (TT) injections by pregnant mothers, targeting vulnerable groups like young, first time and Scheduled Caste mothers, and improving overall household environment by increasing access to improved toilets, electricity, and pucca houses could also contribute to further reductions in neonatal mortality in rural India. Any public health interventions aimed at reducing neonatal death in rural India should consider these factors. 


\section{Introduction}

The major public health interventions during last two decades have been focused on reduction in infant and child mortality [1,2]. As a result, the number of deaths among under-five children has fallen from about 12 million to about 7.2 million during 1990-2011 [3, 4, 5]. Yet, it remains a cause for concern because the annual rate of decline has been only 2.1\% compared to the Millenium Development Goal-4 (MDG-4) target of $4.4 \%[4,6]$ and neonatal deaths still comprise about $40 \%$ of all underfive deaths worldwide [7].

About $98 \%$ of all neonatal deaths occur only in developing world while developed countries account for rest of the neonatal deaths [8,9]. It has been noted that the reduction in neonatal mortality is slower than post-neonatal and childhood mortality, particularly in low and middle-income countries $[4,10,11,12,13]$ which has resulted in an increase in the share of neonatal mortality in overall under- 5 mortality from $39 \%$ in 1970 to $41 \%$ in 2010 [4, 13, 14, 15]. Similalry in India too, which accounts for about one-fourth of all neonatal deaths occurred around the world and has achieved substantial reductions in mortality [16], the share of neonatal deaths in underfive deaths has been increasing over time - from 45\% in 1990 to $54 \%$ in 2010 [4]. This trend indicates a slower reduction in neonatal mortality compared to post-neonatal and childhood mortality during last two decades in India [17]. Nevertheless, the child survival programs in India have been focusing more on the causes of mortality and morbidity which mostly affect children in post-neonatal period - such as pneumonia, malaria, diarrhea, and vaccine-preventable diseases [18] rather than factors such as prematurity, low birth weight and neonatal infections [19, 20, 21, 22].

It is argued that neonatal mortality could be reduced up to $70 \%$ only by evidence-based interventions and strategies [23, 24, 25]. However, to adopt a focused and evidence-based approach to reduce neonatal mortality in India, a clear understanding of the associated factors is necessary. A review of past studies on this issues reveals that although there are many studies examining the factors affecting neonatal mortality available elsewhere in the world [3, 25, 31, 32, 33, 34, 35, 36], the issue seems to be understudied in India. Although there is a large body of literature available describing levels, trends and differentials in infant and child mortality at national and sub-national level $[37,38,39,40,41,42,43,44,45,46]$, existing studies on neonatal mortality are generally 
limited to small geographical areas $[17,47,48,49]$. This study, therfore, aims to examine the effect of various determinants - socio-demographic, economic, healthcare, and community - on neonatal mortality in rural India. The focus is on rural India because about two-thirds (69\%) of the Indian population still lives in the rural areas [26] and suffers from poor early life health condition such as high infant and child mortality compared to its urban counterpart $[27,28,29]$.

This study is different from previous studies in three important ways. Firstly, we examine the effects of variables representing different components of the health system and socio-economic development of villages. Secondly, we try to estimate the effects of household environment separately by including variables related to toilet, water, housetype and electricity in the analysis. Finally, unlike previous studies on neonatal mortality in India, we use the two-level binary logistic regression which takes into account hierarchical structure of the data and provides correct standard errors.

\section{Data and Methods}

\section{Ethics statement}

This study uses anonymised survey data made available for academic use, for which ethical approval is not required. The survey data used in this study can be obtained by making a formal request on the official website (http://www.rchiips.org/) of the International Institute for Population Sciences, Mumbai (India) [50].

\section{Data}

We use data from the third round of the District Level Household Survey (DLHS-3) conducted during 2007-08. It is a large scale, nationally representative, multi-round survey covering more than 700,000 households from 601 districts in 34 States and Union Territories of India. DLHS-3, like its former versions DLHS-1 and DLHS-2, was basically designed to provide reliable information on reproductive and child health (RCH) indicators at district level [50].

The survey adopted a multi-stage stratified probability proportional to size (PPS) sampling design. The details of the survey design, implementation and response rate are given in the DLHS-3 report. DLHS-3 collected information from 720,320 households, 643,944 ever married women aged 15-49 years. Rural sample covered 559,663 
households and 504,272 ever-married women [50]. In this study, we use information on 171,529 infants nested in 22,587 PSUs. We refer to PSU as village or community hereafter in the text.

\section{Conceptual Framework}

Moseley and Chen (1984) proposed a framework that corrected the flaws in previous frameworks used by social scientists and medical scientists to study child mortality. It puts forward a set of proximate determinants that directly influences the risk of child mortality. It also proposes that all other socio-economic factors must operate though this set of proximate determinants [51]. This framework given below has been modified for the present study [25] and displays pathways and selected potential predictors relevant to the present study.

\section{[Figure 1 here]}

\section{Exposure variable}

The neonatal death is the outcome variable in the study. It is defined as "any death occurred during first 28 completed days of life”. Neonatal death is recoded as a binary variable in this study where ' 0 ' indicates that the child survived for more than 28 days and ' 1 ' indicates otherwise i.e. death of the child within 28 days. We have considered only singleton live births (i.e. all births excluding still births and twin births) in the analysis.

\section{Independent variables}

Table 1 lists all explanatory variables, their definitions and categories used in this study. These variables can be divided into four categories - community characterisitcs, individual/household characterisitcs, household environment characterisitcs and proximate determinants. The individual level socio-economic variables included in this study are maternal and paternal education, maternal religion and caste, employment status of the mother and asset index.

The asset index in this study has been used as the proxy for economic status of the household [53, 54, 55, 56, 57, 58]. The asset index is based on variables related to household amenities. The variables included are - mattress, cooker, chair, sofa set, cot, table, fan, radio, black \& white television, color television, sewing machine, mobile phone, telephone, fridge, watch, bicycle, scooter, cart, car, tractor, pump, thresher, cooking fuel 
used, landholdings, and number of rooms in the house. However, it does not include variables representing household environment (type of house, availability of electricity, access to improved water and sanitation) because we wish to separate the effects of these variables later in the analysis. We use the Principal Component Analysis (PCA) to construct the index. The index is divided into three categories - Poor, Middle, Rich..

\section{Statistical Analysis}

The contingency table and two-level logistic regression analysis is used to examine the the factors affecting neonatal mortality in rural India. Descriptive analysis is used to understand the differentials in neonatal deaths across the selected covariates. Unadjusted odds of neonatal mortality are then calculated and only statistically significant variables are retained for the subsequent analysis. To estimate the adjusted effects of different individual, household and community level factors on neonatal mortality, we use a two-level binary logistic regression [59]. We choose a two-level regression technique instead of simple regression analysis because it can take into account the hierarchical structure of the study sample in which individuals (children) are nested within communities (PSUs). Multilevel models allow for such datasets and produce standard errors (SEs) adjusted for clustering of observations [60, 61, 62]. On the other hand, if SEs are estimated using simple binary logistic regression model, there is a chance of underestimation of SEs which could affect the interpretation of the results.

Before applying the two-level regression, we examined the extent to which the outcome of interest varies at higher levels. We fitted a null model and carried out the Wald test to know whether residuals at village level are statistically significant (results not shown). We found that the Wald statistics was highly significant (result not shown) which suggested that fitting a two-level model made sense in this context [63]. We looked for the evidence of multicollinearity using variance inflation factor (VIF) as a post-estimation procedure. It initially revealed that the variable measuring antenatal care (ANC timing and frequency) had a very high VIF. Therefore, we removed it from the regression analysis. The small value of VIF (1.68) from the final regression model indicated the absence of any significant collinearity among the variables. The result of logistic regression is presented in the form of odds ratios with statistical significance shown by $p$-values. The statistical analysis for this study was performed with the help of statistical software Stata 12 SE and MLwiN $2.24[64,65]$. 


\section{Results}

To identify the associated predictors of neonatal mortality in rural India, 171,529 singleton live births to currently married women within 3 years preceding the survey (2004-07) were included in the analysis as the study population. We found that 2892 neonatal deaths occurred, which was $1.68 \%$ of total singleton live births, during this period.

The characteristics of the study variables are presented in Table 2. Around 50\% of neonates were born to mothers who were illiterate. Only $6 \%$ of children were born to mother working as Professional/service/production worker. A great majority of neonates were born to mother living in Kachcha or Semi-Kachcha houses (81\%) and without any improved sanitation facility (71\%). About $12 \%$ of children were born to adolescent mothers and about thre-fourths to Hindu women. About 30\% mother never had antenatal check-up, 38\% mothers did not have adequate IFA and about $47 \%$ did not receive TT injection. A little more than $60 \%$ deliveries occurred at home. About $62 \%$ children were born to women who suffered from at least one delivery related complication.

Table 3, 4, 5 and 6 present crude and adjusted odds ratios for neonatal mortality according to background characterisitcs. Unadjusted odds ratios revealed that some variables like accessibility by an all-weather road, place of delivery and consumption of adequate IFA did not turn out to be statistically significant. We dropped these variables in further analysis. The results of two-level logistic regression revealed that there was a great variation in the odds of neonatal mortality by region. Lower odds of neonatal death were observed in almost all the regions compared to the Central region. The odds of neonatal death were $19 \%$ lower in rich villages compared to poor villages. It was also seen that the odds of neonatal death in villages, where the nearest government health facility is located one to five kilometers away, were 33\% lower than the villages where the nearest public health facility is located within one kilometer from the village (Table 3).

At individual level, mother's education was significantly associated with a reduction in the odds of neonatal deaths. However, this is not true for all literate or educated women. There appears to be a threshold number of years of schooling needed for significant reduction in neonatal mortality. Infants born to mothers with more than 10 years of schooling were about $60 \%$ less likely to experience neonatal death compared to those 
born to illiterate mothers. The same is true about father's education. The odds of neonatal mortality reduced significantly by $15 \%$ and $24 \%$ among children, whose fathers had their schooling up to 'secondary' and 'above secondary' level, respectively, compared to children belonging to illiterate fathers. The caste of the child also emerged as a significant predictor. The odds of neonatal death reduced by $28 \%$ and $13 \%$ in Scheduled Tribes and Others category of castes, respectively, compared to Scheduled Caste children. The odds decreased significantly by $10 \%$ among the neonates of unemployed mothers compared to the neonates of those working as farmers / laborers / agricultural workers (Table 4).

All of household environment variables appeared as significant predictors of neonatal mortality even after controlling for other factors. Children from households with access to an improved source of water were $13 \%$ more prone to death in neonatal period compared to those belonging to households with no accessibility to an improved source of water. Having an improved toilet facility and the electricity in the household reduced the odds of neonatal death significantly by $13 \%$ and $16 \%$ as compared to the household where these facilities were not available. The odds of neonatal death decreased by $13 \%$ among children belonging to households living in a pucca house compared with those living in Kachcha houses (Table 5).

Among the proximate determinants, all variables included in the analysis were found to be significant except the variable for time and frequency of ANC visits of the mother although results were in the expected direction. Increasing mother's age at birth reduced the odds of neonatal death. The odds decreased significantly by $15 \%$ and $26 \%$ respectively among children whose mothers were 20-24 and 25-29 years old, respectively, at the time of their birth compared to children of adolescent mothers. Boy neonates in rural India were found to be $21 \%$ more prone to neonatal death compared to girl neonates. Another demographic variable found significantly related to the reduced risk of neonatal mortality was their birth order. The odds of neonatal death reduced by $35 \%, 42 \%$, and $38 \%$ for second, third and 'four and above' birth orders, respectively, compared to the first birth order. In comparison to the mothers who received only one TT injection during pregnancy, the odds of neonatal death were significantly lower ( $\mathrm{OR}=0.65, p=0.00)$ among those infants whose mothers had two or more TT injections. Similarly, mothers who didn't receive any TT injection, their infants were too about $25 \%$ less at the risk of death in the neonatal period compared to those who had received one TT injection. The risk of neonatal death increased by $20 \%$ if the mother experienced any delivery PeerJ reviewing PDF | (v2013:01:230:2:0:NEW 21 Apr 2013) 
complications compared to those mothers who did not experience any of the delivery complications (Table 6).

\section{Discussion}

In this study, we used the most recent data available in public domain to examine the factors affecting neonatal mortality in rural areas of India. Estimates based on two-level logistic regression model indicate that a number of factors were significantly associated with neonatal mortality. Our findings revealed that maternal education significantly reduced the odds of neonatal death in rural India. The finding is similar to previous studies which have established a link between mother's education and child survival [67, 68, 69, 70, 71]. Maternal education is argued to improve child health through increased knowledge about the practices to improve child health [68] and increased use of maternal cares services [72 73]. Similarly, father's education was also found important for reduction in neonatal deaths.

Results indicated that neonates belonging to ST and 'Others' caste groups were less likely to die before one month compared to SC children. STs have remainedone of the most socioeconomically deprived communities in India since centuries [74]. A large majority of them lives in inaccessible and far-off place which are still underdeveloped [75]. Yet, significantly lower odds of deaths as compared to ST neonates appears quite strange and is a matter of further investigation. The lower risk of neonatal death among 'Others' neonates compared to SC neonates is not surprising because 'Others' castes has been economically better off and socially and politically privileged [76].

Children belonging to the mothers who stayed at home (unemployed) were less likely to die during neonatal period compared to the children belonging to the mothers who worked as farmers/agricultural workers/ laborers. The finding is similar to that of previous studies [25, 77]. It is worth mentioning here that unemployed mothers in rural India were more educated (44\% versus $19 \%$ ) and richer (40\% versus $18 \%$ ) than those who worked as farmers/agricultural workers/laborers (data not shown in tables). This coupled with enough available time for seeking antenatal care and taking care of her neonate (like breastfeeding) could explain the significant decline in the odds of neonatal death [78, 79, 80]. On the other hand, there was no significant difference between the odds of neonatal mortality among mothers who worked as professional/service/production workers and 
farmers/agricultural workers/ laborers. This is supported by the findings of previous studies [71. 81].

All four variables - improved source of drinking water, improved sanitation, type of house, and availability of electricity - included to represent the household environment appeared as significant predictors of neonatal deaths in rural India. Access to improved water actually increased the risk of neonatal death in rural India. It is worth noting here that the relationship of access to an improved source of drinking water with neonatal mortality has been ambiguous. It has shown both positive [34] and negative effects [71] on neonatal mortality. At first, it seems to be a peculiar result in itself. Newborn babies after all are not directly affected by the source of water. Nevertheless, it is plausible that they are indirectly affected. In the case of rural India, the access to improved water sources like a hand-pump within the premises probably leads to more use of water compared to the households where the source of water is located away from the house. However, in the absence of proper drainage, (only 4\% of Indian households had any underground or covered pucca drainage system in 2011) the household wastewater stagnates or stays in the open drainages in and around the house (NSSO $58^{\text {th }}$ round) [82]. This coupled with mud floors (according to Census of India 2011, about 62\% rural houses have mud floors) create an infectious environment which could help spread malaria, diarrhea, and other infectious diseases in both the mother and the newborn [83]. In previous studies too, the two waterborne diseases - maternal malaria among pregnant mothers (causes anemia in mothers during pregnancy and subsequent low birth weight of the newborn) and diarrhea among neonates - have been found to be among the main causes of neonatal death in the developing countries [84, 85, 86, 87, 88, 89, 90, 91]. Since, the purpose of this study is not to catalogue and investigate the different channels through which source of water could affect the chances of neonatal death, a further exploration is needed on this issue.

Three other variables representing household environment - availability of improved toilets, pucca house and electricity - were found to reduce the likelihood of neonatal death. Access to improved toilet reduces the risk of dying through the mechanism of less exposure of neonates to contamination making them less susceptible to diseases and infections, and eventually the death [35]. Pucca houses, by replacing mud walls and thatched/mud roofs of Kachcha houses with brick walls and concrete/brick roofs, provide better shelter from harsh weather conditions especially during monsoon season. 
Availability of elelctricity may help to create better environmental conditions in the house for the newborn [92]. It not only helps in hygienic preparation of food but also encourages the use of electric fan, television and radio.

Among five proximate determinants included in the analysis, mother's age was found to be significantly associated with reduction in neonatal mortality [25, 71]. Older mothers not only possess better knowledge of pregnancy and childbirth but also enjoy greater autonomy compared to younger mothers which help them take care of their neonates in a better way in this period [93, 94]. It also emerges from the analysis that the risk of neonatal death decreases with increasing birth order of the child. These results confirm the results of many studies of the past conducted in different settings around the world $[25,71,95,96,97,98]$. A strong association has been previously reported between the sex of the child and neonatal mortality [35, 98, 99, 100]. Similarly, in this study too, we find that the boys are more susceptible to death within the first month after birth compared to girls. It has been argued that boys are biologically weaker than girls due to various reasons [101, 102, 103]. These reasons include immunodeficiency [102] leaving baby boys more vulnerable to infectious diseases [17], late maturity [104] resulting in a higher prevalence of respiratory diseases in males, and congenital malformations of urogenital system.

The main causes of neonatal mortality are intrinsically linked to the health of the mother and the care she receives during pregnancy and delivery. Our findings indicates that one of the components of antenatal care (TT injection) is significantly associated with lower risk of neonatal deaths. Our study confirmed the results of previous studies that using two or more TT injections during pregnancy help reducing neonatal deaths substantially through reducing the likelihood of tetanus infection in newborns $[91,106,107,109,110,111]$. It has been noted that neonatal tetanus is one of the major causes of neonatal deaths in developing countries [91,106,107,108]. Being an effective strategy to reduce the number of maternal and newborn deaths due to tetanus, increasing the coverage of TT injections could be an important interventions in rural India.

It is well established now that delivery complications cause poor neonatal outcomes as indicated by low apgar scores and low arterial cord blood $\mathrm{pH}$. Confirming the same, our study also found that the neonates born to women, who experienced complications like vaginal bleeding, fever or convulsions during delivery, had remarkably higher odds of 
neonatal death compared to those born to women without any complications during delivery. However, higher odds of neonatal deaths can also be attributed to mothers' inability to take care of their newborn properly in the postnatal period as they themselves take time to recover from the damage due to complications during birth. The findings are consistent with many other studies in the South Asian setting [25,112,113].

At the community level, the prosperity of the villages (as measured by proportion of richest households in the PSU) had a significant influence on neonatal mortality. It is generally argued that community factors, such as overall level of wealth and education in the community, may influence the individual's behaviour, partly through social learning and social influence. It has also been argued that if mothers are more wealthy in a community, they are likely to be more educated and have better knowledge of health care behaviour. Their knowledge and attitudes may be passed on to other women. It is very much possible in a rural Indian setting, where communities are socially more cohesive than urban India. The consequences of such social influence and learning from educated mothers may include better nutrition, adequate and timely vaccination, home care, a hygienic household environment, and interaction with health workers [114, 115, 116].

Quite surprisingly, we found that any increase in the distance to the nearest private health facility decreased the odds of neonatal death. Though it is inconsistent with most of the previous studies conducted in different settings around the world, a study in Pakistan, a neighboring country, has found similar patterns existing [117]. Such results might be attributed to purposeful outreach by health workers or some other unknown situations, however, the issue needs a further exploration.

The 'region' of residence is also significantly associated with the risk of neoneatal death. It was found that neonates from 'South' and 'West' regions were less likely to die in neonatal period. Higher levels of socioeconomic development and better functioning of the healthcare system could be some of the factors behind the better performance of states in these regions. The states covered under Central regions included Madhya Pradesh and Uttar Pradesh (including Uttarakhand, Chhattisgarh). These states are characterized by comparatively poor socioeconomic and demographic indicators and dysfunctional government health care system. Hence, it is not surprising that most of the regions show lower odds of neonatal death compared to Central region. 
Although this study identified important determinants of neonatal mortality in rural India, it has a few limitations. Firstly, we could not include many other community level variables that possibly have an effect on neonatal mortality because they were not available in the dataset that we used. Such variables might include service supply environment such as quality, quantity, and the adequacy of the services; beliefs and traditions about pregnancy and motherhood prevailing in the community. Secondly, some variables like employment of the mother and asset index represented the conditions of the time of the interview, not of the time when the child was born.

\section{Conclusion}

To conclude the study, we can say that the growing share of neonatal mortality in under-five mortality warrants adoption of comprehensive strategies to further reduce the neonatal mortality in rural India. Although a continuum of health care during pregnancy, childbirth, and even during the postnatal period [17, 25] is necessary for further reductions in neonatal mortality, ensuring uptake of an adequate quantity of TT injections during pregnancy should be a priority in maternal and child health related programmatic interventions and strategies [118, 119]. Certain groups of children and women, such as neonates of first birth order, neonates belonging to Scheduled Castes, adolescent mothers and mothers working in agricultural sector need special attention. Targeting these groups in order to provide the continuum of essential maternal and childcare would be a crucial step if neonatal mortality in rural India has to be further reduced. In addition to that, improving the overall household environment by increasing access to improved toilets, electricity and pucca houses could also contribute to further reductions in neonatal mortality in rural India.

\section{References:}

1. World Health Organization (WHO) (2005) MDG: Health and the Millennium Development Goals. World Health Organization, Geneva.

2. United Nations (1995) International Conference on Population and Development: Summary of the Programme of Action. Available at http://www.un.org/ecosocdev/geninfo/populatin/icpd.htm accessed on 21st July 2012.

3. Bhutta ZA, Darmstadt GL, Hasan BS, Haws RA (2005) Community-Based Interventions for Improving Perinatal and Neonatal Health Outcomes in Developing Countries: A Review of the Evidence. Pediatrics 115:519-617. 
4. Rajaratnam JK, Marcus JR, Flaxman AD, Wang H, Levin-Rector A, Dwyer

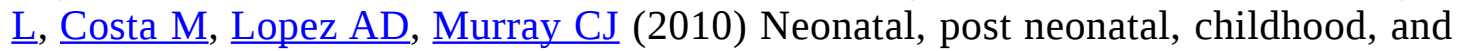
under-5 mortality for 187 countries, 1970-2010: a systematic analysis of progress towards Millennium Development Goal 4. The Lancet 375(9730):1988-2008.

5 .

Lozano R, Wang H, Foreman KJ, Rajaratnam JK, Naghavi M, Marcus JR, Lindgren LD, Lofgren KT, Phillips D, Atkinson C, Lopez AD, Murray CJL (2011) Progress towards Millennium Development Goals 4 and 5 on maternal and child mortality: an updated systematic analysis. The Lancet 378(9797):1139-1165

6. Murray CJL, Laakso T, Shibuya K, Hill K, Lopez AD. Can we achieve Millennium Development Goal 4? New analysis of country trends and forecasts of under-5 mortality to 2015.Lancet2007; 370:1040-54.

7. Liu L, Johnson HL, Cousens S, Perin J, Scott S, Lawn JE, Rudan I, Campbell H, Cibulskis R, Li M, Mathers C, Black RE; Child Health Epidemiology Reference Group of WHO and UNICEF (2012) Global, regional, and national causes of child mortality: an updated systematic analysis for 2010 with time trends since 2000. Lancet 379(9832):2151-61.

8. Åhman E, Zupan J (2007) Neonatal and perinatal mortality: country, regional and global estimates 2004. Geneva. World Health Organisation.

9. Oestergaard MZ, Inoue M, Yoshida S, Mahanani WR, Gore FM, Cousens S, Lawn JE, Mathers CD; United Nations Inter-Agency Group for Child Mortality Estimation and the Child Health Epidemiology Reference Group (2011) Neonatal Mortality Levels for 193 Countries in 2009 with Trends since 1990: A Systematic Analysis of Progress, Projections, and Priorities. PLoS Medicine 8(8):e1001080.

10. Black RE, Cousens S, Johnson HL, Lawn JE, Rudan I, Bassani DG, Jha P, Campbell H, Walker CF, Cibulskis R, Eisele T, Liu L, Mathers C; Child Health Epidemiology Reference Group of WHO and UNICEF (2010) Global, regional, and national causes of child mortality in 2008: a systematic analysis. The Lancet 375(9730):1969-87.

11. United Nations International Children's Emergency Fund (2008) The state of the world's children 2009. New York: UNICEF.

12. You D, Wardlaw T, Salama P, Jones G (2010) Levels and trends in under-5 mortality, 1990-2008. The Lancet 375(9709):100-3

13. Lawn JE, Cousens S, Zupan J (2005) 4 million neonatal deaths, When? Where? Why? The Lancet 365: 891-900.

14. Zupan J, Aahman E (2005) Perinatal mortality for the year 2000: estimates developed by the WHO. Geneva: World Health Organization.

15. United Nations (UN) (2001) Road map towards the implementation of the United Nations Millennium Declaration: report of the Secretary-General. New York: United Nations.

16. Office of Registrar General of India (ORGI) (2008) Sample Registration System Report 2008. New Delhi, Government of India.

17. Arokiasamy P, Gautam A (2008) Neonatal mortality in the empowered action group states of India: trends and determinants. Journal of Biosocial Science 40(2):183-201. 
18. Bhargave SK (2004) The challenge of neonatal mortality in India. Indian Pediatrics 41:657-662.

19. Baqui AH, Darmstadt GL, Williams EK, Kumar V, Kiran TU, Panwar D, Srivastava VK, Ahuja R, Black RE, Santosham M (2006) Rates, timing and causes of neonatal deaths in rural India: implications for neonatal health programmes. Bulletin of the World Health Organisation 84(9): 706-713.

20. The Million Death Study Collaborators (2010) Causes of neonatal and child mortality in India: nationally representative mortality survey. The Lancet 376(9755):1853-1860. doi:10.1016/S0140-6736(10)61461-4.

21. Bang AT, Reddy HM, Bang RA, Deshmukh MD (2005) Why do neonates die in rural Gadchiroli, India? (Part II): estimating population attributable risks and contribution of multiple morbidities for identifying a strategy to prevent deaths. Journal of Perinatology 25(Suppl1):S35-43.

22. Tinker A, Hoope-Bender P, Azfar S, Bustreo F, Bell R (2005) A continuum of care to save newborn lives. The Lancet 365: 822-825.

23. Darmstadt GL, Bhutta ZA, Cousens S, Adam T, Walker N, De Bernis L, Lancet Neonatal Survival Steering Team (2005) Evidence-based, cost-effective interventions: how many newborn babies can we save? The Lancet 365(9463):977-988.

24. Yinger NV, Ransom EI (2003) Why invest in newborn health: policy perspectives on newborn health. In Policy Perspectives on Newborn Health. Save the Children and Population Reference Bureau 1-6.

25. Titaley CR, Dibley MJ, Agho K, Roberts CL, Hall J (2008) Determinants of neonatal mortality in Indonesia. BMC Public Health 8:232.

26. Office of the Registrar General and Census Commissioner, India (2011) Provisional Population Totals Paper 1 of 2011 India Series-1. New Delhi, Government of India.

27. Ministry of Finance (2011) Economic Survey 2011-12. Government of India. Available at http://www.indiabudget.nic.in/survey.asp accessed on 24th July 2012

28. Robin S. Lau, Shanthi Johnson and T. J. Kamalanabhan (2012) Healthy Life Expectancy in the Context of Population Health and Ageing in India Asia Pacific Journal of Public Health 24:195

29. International Institute for Population Sciences (IIPS) \& Macro International (2007) National Family Health Survey (NFHS-3), 2005-06: India, Volume I. Mumbai: IIPS.

30. Office of Registrar General of India (ORGI) (2010) Sample Registration System Report 2010. New Delhi, Government of India.

31. Shakya K, McMurray C (2001) Neonatal mortality and maternal health care in Nepal: Searching for patterns of association. Journal of Biosocial Science 33:87-105

32. Samms-Vaughan ME, McCaw-Binns A M, Foster-Williams K (1990) Neonatal mortality determinants in Jamaica. Journal of Tropical Pediatrics 36:171-175

33. Machado CJ and K Hill (2003) Determinants of neonatal and post neonatal mortality in the city of Sao-Paulo. Brazilian Journal of Epidemiology, 6(4):345-358

34. Mahmood MA. (2004) Determinants of Neonatal and Post-neonatal Mortality in Pakistan. The Pakistan Development Review 41(4) 723-74 
35. Rahman MM, Abidin S (2010) Factors Affecting Neonatal Mortality in Bangladesh Journal of Health Management 12: 137

36. Diallo AH, Meda N, Zabsonré E, Sommerfelt H, Cousens S, Tylleskär T, PROMISE-EBF Study Group (2010) Perinatal mortality in rural Burkina Faso: a prospective community-based cohort study. BMC Pregnancy Childbirth 17;10:45

37. Jain A (1985) Determinants of regional variations in infant mortality in rural India. Population Studies 39(3): 407-424

38. Gupta M (1990) Death clustering, mothers' education and the determinants of child mortality in rural Punjab, India. Population Studies 44(3):489-505.

39. Simmons GB, Smucker C, Bernstein S, Jensen E (1982) Post-Neonatal Mortality in Rural India: Implications of an Economic Model. Demography 19(3): 371-389.

40. Narayana D (2008) Intensifying Infant Mortality Inequality in India and a Reversal by Policy Intervention. Journal of Human Development and Capabilities, 2008, 9(2):265-281

41. S.V. Subramanian SV, Nandy S, Irving M, Gordon D, Lambert H, Smith GD (2006) The Mortality Divide in India: The Differential Contributions of Gender, Caste, and Standard of Living Across the Life Course. American Journal of Public Health 96(5): 818-825.

42. Pradhan J, Arokiasamy P (2010) Socio-economic inequalities in child survival in India: a decomposition analysis Health Policy 98(2-3):114-120

43. Joe W, Mishra US, Navaneetham K (2010) Socio-economic inequalities in child health: recent evidence from India. Global Public Health. 5(5):493-508.

44. Behl AS (2012) Trends and Disparities in Child Mortality in India. Indian Pediatriacs pii: S097475591100843-1. [Epub ahead of print]

45. Bhattacharya C, Chikwama C (2011) inequalities in child mortality in India. Asian Population Studies 7(3):243-261

46. Pandey A, Minja KC, Luther NY, Sahu D, Chand J (1998) Infant and Child Mortality in India. National Family Health Survey Subject Reports 11, 1998; International Institute of Population Sciences, Mumbai and East-West Centre Program on Population, Hawaii

47. Kumar C, Singh PK, Rai RK, Singh L. 2012 Early Neonatal Mortality in India, 1990-2006. Journal of Community Health doi: 10.1007/s10900-012-9590-8

48. Bapat U, Alcock G, More NS, Das S, Joshi W, Osrin D (2012) Stillbirths and newborn deaths in slum settlements in Mumbai, India: a prospective verbal autopsy study. BMC Pregnancy Childbirth 30:12:39

49. Singh A, Yadav A, Singh A (2012) Utilization of postnatal care for newborns and its association with neonatal mortality in India: An analytical appraisal. BMC Pregnancy Childbirth 9:12:33.

50. International Institute for Population Sciences (IIPS) (2010) District Level Household and Facility Survey (DLHS-3), 2007-08: India. Mumbai: IIPS.

51. Mosley WH, Chen LC (1984) An Analytical Framework for the Study of Child Survival in Developing Countries. Population and Development Review 10 (supplementary):25-45

52. World Health Organisation (2005) World Health Report 2005: Make every mother and child count. Geneva: World Health Organisation

53. Montgomery MR, Grangnolati M, Burke MKA, Paredes E (2000) Measuring living standards with proxy variables. Demography 37(2):155-174. 
54. Filmer D, Ptitchett H (2001) Estimating wealth effects without expenditure data-or tears: An application to educational enrolments in states of India. Demography 38(1):115

55. Vyas S Kumaranayake L (2006) Constructing socio-economic status indices: how to use principal component analysis. Health Policy and Planning 21(6):459-468. doi: 10.1093/heapol/czl029

56. O’Donnell O, Doorslaer EV, Wagstaff A, Lindelow M (2008) Analysing health equity using household survey data: A guide to techniques and their implementation. World Bank Institute Learning Resource Series, The World Bank, Washington, D.C.

57. Rutstein SO (2008) The DHS wealth index: Approaches to rural and urban areas. Demographic and Health Survey, Working paper number 60, Calverton, MD: Macro International Inc, USA.

58. Howe LD, Hargreaves JR, Gabrysch S (2009) Is the wealth index a proxy for consumption expenditure? A systematic Review. Journal of Epidemiology and Community Health 63(11):871-877.

59. Guang Guo and Hongxin Zhao (2000) Multilevel Modelling for Binary Data. Annual Review of Sociology 26:441-462

60. Diez-Roux AV (2000) Multilevel Analysis in Public Health Research Annual Review of Public Health 21: 171-192 DOI: 10.1146/annurev.publhealth.21.1.171

61. Heck RH, Thomas SL (2009) An Introduction to Multilevel Modelling Techniques. E-edition Taylor and Francis.

62. Blakely TA, Woodward AJ (2000) Ecological effects in multi-level studies. Journal of Epidemiology and Community Health 54:367-374

63. Rasbash J, Steele F, Browne WJ, Goldstein H (2009) A User's Guide to MLwiN, v2.10 Bristol: Centre for Multilevel Modelling, University of Bristol.

64. Stata Corporation (2011) Stata Statistical Software: Release 12. Texas: College Station, StataCorp LP.

65. Rasbash J, Charlton C, Browne WJ, Healy M, Cameron B (2009) MLwiN Version 2.1 Bristol: Centre for Multilevel Modelling, University of Bristol.

66. Nayar KR (2011) India's country experience in addressing social exclusion in maternal and child health. World Conference on Social Determinants of Health, Rio de Janeiro, Brazil 2011. Draft background paper 8 WCSDH/BCKGRT/8/2011 available http://www.who.int/sdhconference/resources/draft_background_paper8_india.pdf accessed on 21st July 2012

67. Basu AM, Stephenson R (2005) Low levels of maternal education and the proximate determinants of childhood mortality: a little learning is not a dangerous thing. Social Science \& Medicine 60: 2011-23.

68. Caldwell JC (1979) Education as a factor in mortality decline: an examination of Nigerian data. Population Studies 33: 395-413

69. Mellington N, Cameron L. 1999. Female education and child mortality in Indonesia. Bulletin of Indonesian Economic Studies 35: 115-44.

70. Ware H. 1984. Effects of maternal education, women's roles, and child care on child mortality. Population and Development Review 10:191-214.

71. Zanini RR, de Moraes AB, Giugliani ERJ, Riboldi J (2011) Contextual determinants of neonatal mortality using two analysis methods, Rio Grande do Sul, Brazil. Revista de Saúde Pública 45(1)

72. Elo IT (1992) Utilization of maternal healthcare services in Peru: the role of women's education. Health Transition Review 2(1):49-69 
73. Shobana Raghupathy S (1996) Education and the use of maternal health care in Thailand. Social Science \& Medicine 43(4):459-471

74. Borooah VK (2005) Caste, inequality and poverty in India. Review of Development Economics, 9(3), 399-414, 2005

75. Mohindra KS, Labonté S (2010) A systematic review of population health interventions and Scheduled Tribes in India. BMC Public Health 10:438

76. Zacharias A, Vakulabharanam V (2011) Caste stratification and wealth inequality in India. World Development 39(10):1820-1833

77. Kishor S, Parasuraman S (1998) Mother's Employment and Infant and Child Mortality in India. National Family Health Survey Subject Reports Number 8. Mumbai, India, International Institute for Population Sciences. Calverton, Maryland, U.S.A., Macro International Inc.

78. Basu, AM, Basu K (1991) Women's Economic Roles and Child Survival: The Case of India. Health Transition Review 1: 83-103.

79. Hobcraft J (1993) Women's education, child welfare and child survival: a review of the evidence. Health Transition Review 3(2):159-173

80. Tulasidhar VB (1993) Maternal education, female labour force participation and child mortality: evidence from the Indian census. Health Transition Review 3(2):177-189

81. Murthi, Mamta, Anne-Catherine Guio, and Jean Dreze. 1995. Mortality, fertility, and gender bias in India: A district-level analysis. Population and Development Review 21(4):745-82.

82. Office of the Registrar General and Census Commissioner of India (2011) Houselisting and Housing Census Data Highlights - 2011. New Delhi, Government of India. Available at - http://www.censusindia.gov.in, accessed on $24^{\text {th }}$ July 2012.

83. Rath S, Nair N, Tripathy PK, Barnett S, Rath S, Mahapatra R, Gope R, Bajpai A, Sinha1 R, Costello A, Prost A (2010) Explaining the impact of a women's group led community mobilisation intervention on maternal and newborn health outcomes: the Ekjut trial process evaluation. BMC International Health and Human Rights 10:25

84. Hartman TK, Rogerson SJ, Fischer PR (2010) The impact of maternal malaria on newborns. Annals of Tropical Paediatrics 30(4):271-82.

85. Yilgwan CS, Hyacinth HI, Oguche S (2011) Factors associated with decreased survival from neonatal malaria infection in Jos, North Central Nigeria. Nigerian Journal of Medicine 20(3):349-54.

86. Rijken MJ, Papageorghiou AT, Thiptharakun S, Kiricharoen S, Dwell SLM, et al. (2012) Ultrasound Evidence of Early Fetal Growth Restriction after Maternal Malaria Infection. PLoS ONE 7(2): e31411. doi:10.1371/journal.pone.0031411

87. Yakoob MY, Ali MA, Ali MU, Imdad A, Lawn JE, Broek NVD, Bhutta ZA (2011) The effect of providing skilled birth attendance and emergency obstetric care in preventing stillbirths BMC Public Health. 2011; 11(Suppl 3): S7.

88. Lawn JE, Lee AC, Kinney M, Sibley L, Carlo WA, Paul VK, Pattinson R, Darmstadt GL (2009) Two million intra-partum related stillbirths and neonatal deaths: where, why, and what can be done? International Journal of Gynaecology and Obstetrics 107: S5-19

89. Ghosh R (2010) Child mortality in India: a complex situation. World Journal of Pediatrics 8(1):11-18 
90. Titaley CR, M J Dibly, CL Roberts, J Hall and K Agho (2009) Iron and Folic Acid supplements and reduced early neonatal deaths in Indonesia. Bulletin of the World Health Organization 2010;88:500-508

91. Taha TE, Gray RH, Abdelwahab MM (1993) Determinants of neonatal mortality in central Sudan. Annals of Tropical Paediatrics 13(4):359-64.

92. Poel EV, Doorsleaer EV (2009) What Explains the Rural-Urban Gap in Infant Mortality: Household or Community Characteristics. Demography 46(4):827-850

93. O'Malley AS, Forrest CB (2002) Beyond the examination room: primary care performance and patient-physician relationship for low income women. Journal of General Internal Medicine 17:66-74

94. Hobcraft J, Kiernan K Childhood poverty, early motherhood and adult social exclusion. British Journal of Sociology 52(3):495-517

95. Rutstein OS, (1984) Infant and Child Mortality: Levels, Trends, and Demographic Differentials. Revised edition. WFS Comparative Studies No. 43. Voorburg, Netherlands: International Statistical Institute.

96. Yerushalmy J (1938) Neonatal mortality by order of birth and age of parents. American Journal of Hygeine 28(2):244-70.

97. Hussain R (2002) Risk factors for neonatal mortality in low-income population subgroups in Karachi, Pakistan. Community Genet. 5(4):249-56.

98. Rahman M, Huq SS (2009) Biodemographic And Health Seeking Behavior Factors Influencing Neonatal And Postneonatal Mortality In Bangladesh: Evidence From DHS Data. East African Journal of Public Health 6(1)

99. Chaman R, Naieni KH, Golestan B, Nabavizadeh H, Yunesian M (2009) Neonatal Mortality Risk Factors in a Rural Part of Iran:A Nested Case-Control Study Iranian Journal of Public Health 38(1):48-52

100. Machado CJ, Hill K (2005) Maternal, neonatal and community factors influencing neonatal mortality in Brazil. Journal of Biosocial Science 37(2):193-208.

101. Ulizzi L, Zonta LA (2002) Sex differential patterns in perinatal deaths in Italy. Human Biology 74: 879-88

102. Green MS (1992) The male predominance inthe incidence of infec-tious diseases in children: a postulated explanation for dis-parities in the literature. International Journal of Epidemiology 21(2):381-386.

103. Mahy M (2003) DHS Comparative Reports No 4: Childhood mortality in the developing world: a review evidence from the demographic and health surveys Calverton: ORC Macro.

104. Alonso V, Fuster V, Luna F (2006) Causes of neonatal mortality in Spain (1975-98): Influence of sex, rural-urban residence and age at death. Journal of Biosocial Science 38(4):537-551.

105. Shakya K, McMurray C (2001) Neonatal mortality and maternal health care in Nepal: searching for patterns of association. Journal of Biosocial Science 33(1):87-105.

106. Rahman M, Chen LC, Chakraborty J, Yunus M, Chowdhury AI, Sarder AM, Bhatia S, Curlin G T (1982) Use of tetanus toxoid for the prevention of neonatal tetanus.1.Reduction of neonatal mortality by immunization of non-pregnant and pregnant women in rural Bangladesh. Bulletin of the World Health Organization 60(2):261-267

107. Gupta SD, Keyl PM (1998) Effectiveness of prenatal tetanus toxoid immunization against neonatal tetanus in a rural area in India. The Pediatric infectious disease journal 17:316-21. 
108. Vandelaer J, Birmingham M, Gasse F, Kurian M, Shaw C, Garnier S (2003) Tetanus in developing countries: an update on the Maternal and Neonatal Tetanus Elimination Initiative. Vaccine 21(24):3442-5.

109. Yusuf B, Solter S, Bertsch D, Arnold RB (1991) Impact of a tetanus toxoid immunization mass campaign on neonatal tetanus mortality in Aceh Province, Indonesia. Southeast Asian Journal of Tropical Medicine and Public Health 22:351-356.

110. Blencowe H, Lawn J, Vandelaer J, Roper M, Cousens S (2010) Tetanus toxoid immunization to reduce mortality from neonatal tetanus. International Journal of Epidemiology 39(suppl 1):i102-i109

111. Arnold RB, Soewarso TI, Karyadi A (1986) Mortality from neonatal tetanus in Indonesia: results of two surveys. Bulletin of World Health Organization 64:259-62.

112. Titaley CR, Dibley MJ, Roberts CL (2011) Type of delivery attendant, place of delivery and risk of early neonatal mortality: analyses of the 1994-2007 Indonesia Demographic and Health Surveys

113. Mercer A, Haseen F, Huq NL, Uddin N, Hossain Khan M, Larson CP (2006) Risk factors for neonatal mortality in rural areas of Bangla-desh served by a large NGO programme. Health Policy \& Planning 21(6):432-443.

114. Kravdal O (2004) Child mortality in India: The community-level effect of education. Population Studies: A Journal of Demography 58(2): 177-192

115. Parashar S (2005) Moving beyond the mother-child dyad: women's education, child immunization, and the importance of context in rural India. Social Science and Medicine 61(5):989-1000.

116. Moursund A, Kravdal O. (2003) Individual and community effects of women's education and autonomy on contraceptive use in India, Population Studies 57:285-302.

117. Noorali R, Luby S, Rahbar MH (1999) Does use of a government service depend on distance from the health facility? Health Policy and Planning 14(2):191-197

118. Singh A, Pallikadavath S, Ogollah R, Stones W (2012) Maternal Tetanus Toxoid Vaccination and Neonatal Mortality in Rural North India. PLoS ONE 7(11): e48891. doi:10.1371/journal.pone.0048891

119. Ayaz A, Saleem S (2010) Neonatal Mortality and Prevalence of Practices for Newborn Care in a Squatter Settlement of Karachi, Pakistan: A Cross-Sectional Study. PLoS ONE 5(11): e13783. doi:10.1371/journal.pone.0013783 


\section{Table $\mathbf{1}_{\text {(on next page) }}$}

Operational definition and categorization of variables used in the study 
Table 1: Operational definition and categorization of variables used in the study

\begin{tabular}{l}
\hline Variables \\
\hline Community variables \\
Accessibility by an all-weather road \\
Distance to nearest private health facility \\
Distance to nearest public health facility
\end{tabular}

ANM/ASHA available in the village

Janani Suraksha Yojana (JSY) implemented

Proportion of mother with 'above secondary' education

Proportion of rich households

Region

\section{Socioeconomic variables \\ Mother's education}

Father's education

Asset index

Religion

Caste/Tribe

Employment of the mother

Improved source of water

Improved toilet facility

House type

Electricity
Description

Whether the village is accessible by an all-weather road - No (0), Yes (1) Distance to any private health facilities (private hospital or private clinic) to the villages - Within 1 kilometre $(0)=$ within village or within 1 kilometre; 1-5 kilometres (1); More than 5 kilometres (2). Distance to any public health facilities (CHC or PHC or Block PHC or PHC or Government hospital) to the villages - Within I kilometre $(0)=$ within village or within 1 kilometre; 1-5 kilometres (1); More than 5 kilometres (2).

ANM (Auxiliary Nurse and Midwife)/ASHA (Accredited Social Health Worker) resides in or visits the village - No (0), Yes (1). Whether JSY has been implemented in the village -No (0), Yes (1). The proportion of mother with 'above secondary' education in the village.

The proportion of rich households in the villages. It is constructed by combining two upper quintiles of the Household Wealth Index already available in the dataset.

A region in this study is a group of Indian states. North region (1) includes Jammu \& Kashmir, Himachal Pradesh, Punjab, Rajasthan, Haryana, Chandigarh (Union Territory -UT) and Delhi; Central region (2) includes the states of Uttar Pradesh, Uttaranchal, Madhya Pradesh and Chhattisgarh; East region (3) includes the states of Bihar, Jharkhand, West Bengal and Orissa; North-East region (4) includes the states of Sikkim, Assam, Meghalaya, Manipur, Mizoram, Nagaland, Tripura, and Arunachal Pradesh; West region (5) includes the states of Gujarat, Maharashtra, Goa and UTs of Dadara \& Nagar Haveli and Daman \& Diu, South region (6) includes the states of Kerala, Karnataka, Andhra Pradesh, Tamil Nadu and the UTs of Andaman \& Nicobar Islands, Pondicherry and Lakshadweep)

Mother's education is defined based on years of schooling and divided into four categories - Illiterate $(0)=0$ years of schooling; Primary $(1)=1-5$ years of schooling; Below secondary $(2)=6-10$ years of schooling; Above secondary (3) = more than 10 years of schooling. Father's education is defined based on years of schooling and divided into four categories - Illiterate $(0)=0$ years of schooling, Primary (1) =1-5 years of schooling; Below secondary $(2)=6-10$ years of schooling; Above secondary (3) = more than 10 years of schooling. The asset index is estimated using principal component analysis and divided into three categories - Poor (0); Middle (1); Rich (2). Religion is divided into three categories - Hindu (0); Muslims (1); Other (3) = all religious groups other than Hindu and Muslims. Caste/Tribe is divided into four categories - Scheduled Caste - SC (0); Scheduled Tribe - ST (1); Other Backward Castes - OBC (2); General (3).

Mother is said to be employed if a mother was engaged in any economic activity in last 12 months preceding survey. It has been divided into three categories - Agriculture worker, farmer, and labourer (0); Unemployed (1); Professional/service/production workers (2).

Whether the household has access to piped water within the premises of the house - No (0); Yes (1).

Whether the household has access to improved toilet facility - No (0); Yes (1).

Type of house - Kaccha $(0)=$ wall, floors, and roofs are kaccha; Pucca (1) = walls, floors, and roofs are pucca. Whether the household has an electricity connection -No (0); Yes (1). 


\section{Proximate Determinants}

Mother's age at birth

Sex of the child

Tetanus toxoid (TT) Injection

Iron and folic acid (IFA) tablets

Birth order

Delivery complications

Place of delivery and skilled birth attendance (SBA)

Antenatal Care (ANC) visits
Maternal age at birth is divided into four categories $-<20$ years $(0)$; 20-24 years (1); 25-29 years (2); $\geq 30$ years (3).

Sex of the child - Girls (0); Boys (1).

Number of TT injection taken during pregnancy - One (0); Zero (1); Two or more (2)

Consumption of adequate IFA tablets/syrup during pregnancy - No (0); Yes (1).

The order in which the child was born - First order (0); Second order (1); Third order (2); Four and above (3).

Whether mother faced any complication/s during delivery - No (0); Yes (1).

A variable is computed with combination of place of delivery and assistance during delivery by any health personnel. This is divided into three categories - Home (0); Home + SBA (1) = home delivery assisted by any trained health personnel; Health facility (2).

This variable is computed using two variables, the frequency and the timing of ANC visits. This is divided into four categories - No visit $(0)=$ no ANC visit; First trimester $+\geq 4$ visits $(1)=$ Four or more visits in first trimester; First trimester $+<4$ visits $(2)=$ less than four visits in first trimester; ANC visits made in second and third trimester (3).

Note: Categories in italics have been used as reference category in the regression models. 


\section{Table 2 (on next page)}

\section{Characteristics of variables}


Table 2: Characteristics of variables

\begin{tabular}{|c|c|c|c|c|}
\hline Variables & Births $^{*}$ & $\%$ births $^{\S}$ & $\begin{array}{c}\begin{array}{c}\text { Neonatal } \\
\text { deaths }\end{array} \\
\end{array}$ & $\%$ Neonatal deaths ${ }^{\mu}$ \\
\hline \multicolumn{5}{|l|}{ Community characteristics } \\
\hline \multicolumn{5}{|l|}{ Region } \\
\hline Central & 52537 & 29.8 & 1216 & 2.30 \\
\hline North & 10736 & 15.2 & 129 & 1.20 \\
\hline East & 56965 & 23.1 & 1003 & 1.80 \\
\hline North-East & 21141 & 12.6 & 229 & 1.10 \\
\hline West & 13756 & 9.4 & 134 & 1.00 \\
\hline South & 16394 & 9.9 & 218 & 1.30 \\
\hline \multicolumn{5}{|c|}{ Accessibility by an all-weather road } \\
\hline No & 26208 & 15.1 & 434 & 1.63 \\
\hline Yes & 144764 & 84.9 & 2491 & 1.70 \\
\hline \multicolumn{5}{|c|}{ Distance to the nearest private health facility } \\
\hline Within $1 \mathrm{~km}$ & 31,540 & 18.6 & 504 & 1.59 \\
\hline $1-5 \mathrm{Kms}$ & 19,128 & 11.1 & 324 & 1.67 \\
\hline$>5 \mathrm{kms}$ & 120,204 & 70.3 & 2,097 & 1.72 \\
\hline \multicolumn{5}{|c|}{ Distance to the nearest Public health facility } \\
\hline Within 1 km & 31,136 & 18.3 & 484 & 1.54 \\
\hline $1-5 \mathrm{Kms}$ & 2,438 & 1.4 & 27 & 1.09 \\
\hline$>5 \mathrm{kms}$ & 137,329 & 80.3 & 2,413 & 1.73 \\
\hline \multicolumn{5}{|c|}{ ANM/ASHA available/visiting the village } \\
\hline No & 142530 & 83.0 & 2480 & 1.72 \\
\hline Yes & 28442 & 17.0 & 445 & 1.54 \\
\hline \multicolumn{5}{|c|}{ JSY implemented in the village } \\
\hline No & 138795 & 81.18 & 2419 & 1.72 \\
\hline Yes & 32167 & 18.82 & 506 & 1.55 \\
\hline \multicolumn{5}{|c|}{ Individual/socio-economic characteristics } \\
\hline \multicolumn{5}{|c|}{ Mother's education } \\
\hline Illiterate & 85924 & 49.3 & 1710 & 1.97 \\
\hline Primary & 26512 & 15.6 & 458 & 1.70 \\
\hline Secondary & 54422 & 32.4 & 728 & 1.32 \\
\hline$>$ Secondary & 4663 & 2.8 & 33 & 0.69 \\
\hline \multicolumn{5}{|l|}{ Father's education } \\
\hline Illiterate & 47758 & 27.5 & 991 & 2.05 \\
\hline Primary & 29087 & 17.0 & 548 & 1.86 \\
\hline Secondary & 83091 & 48.7 & 1260 & 1.49 \\
\hline$>$ Secondary & 11585 & 6.8 & 130 & 1.09 \\
\hline \multicolumn{5}{|l|}{ Asset Index } \\
\hline Poor & 60496 & 34.8 & 1253 & 2.05 \\
\hline Middle & 56268 & 32.9 & 962 & 1.68 \\
\hline Rich & 54724 & 32.4 & 714 & 1.29 \\
\hline \multicolumn{5}{|l|}{ Religion } \\
\hline Hindu & 131729 & 76.5 & 2355 & 1.76 \\
\hline Muslim & 21936 & 12.6 & 376 & 1.71 \\
\hline Others & 17852 & 10.9 & 198 & 1.09 \\
\hline \multicolumn{5}{|l|}{ Caste } \\
\hline Scheduled Castes & 33069 & 19.5 & 676 & 2.02 \\
\hline Scheduled Tribes & 34631 & 21.2 & 469 & 1.32 \\
\hline Other Backward Castes & 67595 & 39.6 & 1267 & 1.86 \\
\hline General & 32937 & 19.7 & 461 & 1.39 \\
\hline \multicolumn{5}{|c|}{ Employment of the mother $\Omega$} \\
\hline 1 & 95210 & 55.4 & 1490 & 1.91 \\
\hline 2 & 9943 & 5.8 & 156 & 1.54 \\
\hline 3 & 66166 & 38.7 & 1280 & 1.54 \\
\hline \multicolumn{5}{|l|}{ Household environment } \\
\hline \multicolumn{5}{|l|}{ Improved source of water } \\
\hline No & 56415 & 33.0 & 804 & 1.40 \\
\hline Yes & 115106 & 67.0 & 2125 & 1.82 \\
\hline Improved toilet facility & & & & \\
\hline No & 125912 & 72.9 & 2409 & 1.89 \\
\hline Yes & 45606 & 27.1 & 520 & 1.13 \\
\hline
\end{tabular}

PeerJ reviewing PDF | (v2013:01:230:2:0:NEW 21 Apr 2013) 


\begin{tabular}{|c|c|c|c|c|}
\hline \multicolumn{5}{|l|}{ House type } \\
\hline Kaccha & 140470 & 81.8 & 2543 & 1.78 \\
\hline Pucca & 31050 & 18.2 & 386 & 1.23 \\
\hline \multicolumn{5}{|l|}{ Electricity } \\
\hline No & 79810 & 45.3 & 1639 & 2.04 \\
\hline Yes & 91711 & 54.7 & 1290 & 1.39 \\
\hline \multicolumn{5}{|l|}{ Proximate determinants } \\
\hline \multicolumn{5}{|l|}{ Mother's age at birth } \\
\hline$<20$ & 21972 & 12.8 & 538 & 2.42 \\
\hline $20-24$ & 68773 & 40.3 & 1159 & 1.66 \\
\hline $25-29$ & 48555 & 28.3 & 674 & 1.36 \\
\hline$>30$ & 32221 & 18.6 & 558 & 1.71 \\
\hline \multicolumn{5}{|l|}{ Sex of the child } \\
\hline Girls & 79437 & 46.3 & 1223 & 1.52 \\
\hline Boys & 92070 & 53.7 & 1699 & 1.82 \\
\hline \multicolumn{5}{|l|}{ Tetanus Toxoid injection } \\
\hline 1 & 54765 & 31.6 & 1086 & 1.96 \\
\hline 0 & 10750 & 6.5 & 241 & 2.17 \\
\hline 2 or more & 105343 & 61.9 & 1592 & 1.49 \\
\hline \multicolumn{5}{|l|}{ Iron and Folic Acid tablets } \\
\hline No & 81154 & 47.4 & 1396 & 1.69 \\
\hline Yes & 90302 & 52.6 & 1533 & 1.67 \\
\hline \multicolumn{5}{|l|}{ Birth order of the child } \\
\hline 1 & 52975 & 30.1 & 1135 & 2.10 \\
\hline 2 & 44187 & 18.5 & 616 & 1.37 \\
\hline 3 & 29064 & 8.8 & 392 & 1.33 \\
\hline 4 and above & 45250 & 42.6 & 780 & 1.70 \\
\hline \multicolumn{5}{|l|}{ Delivery complications } \\
\hline No & 63862 & 37.8 & 926 & 1.42 \\
\hline Yes & 107659 & 62.2 & 2003 & 1.84 \\
\hline \multicolumn{5}{|l|}{ Place of delivery and SBA } \\
\hline Home & 98407 & 56.7 & 1654 & 1.66 \\
\hline Home + SBA & 9754 & 5.7 & 146 & 1.47 \\
\hline Health Facility & 63287 & 37.6 & 1127 & 1.75 \\
\hline \multicolumn{5}{|c|}{ Time and frequency of ANC visits } \\
\hline No Visit & 51491 & 30.1 & 1027 & 1.97 \\
\hline First trimester $+\geq 4$ visits & 33231 & 20.4 & 424 & 1.26 \\
\hline First trimester $+<4$ visits & 30683 & 18.1 & 493 & 1.59 \\
\hline $\begin{array}{l}\text { Second or third semester } \\
\text { visits }\end{array}$ & 53038 & 31.3 & 948 & 1.77 \\
\hline Total & 171456 & 100.0 & 2929 & 1.69 \\
\hline
\end{tabular}

Note: $\Omega$ Employment of the mother: $1=$ Agricultural worker/farmer/labourer, $2=$ Unemployed, $3=$ Professional/service/production worker; ${ }^{¥}$ some variables had missing cases; ${ }^{\S}$ The percentage of birth is calculated using total number of births i.e. the sample of this study (171456); ${ }^{\mu}$ The percentage of deaths is the percentage of neonatal deaths out of total number of births in the subgroup. For example - the per cent deaths for Central region (2.30) comes from dividing 'Neonatal deaths' (1216) with 'Births' (52537) in Central region; ANM/ASHA stands for Auxiliary Nurse and Midwife/Accredited Social Health Worker; SBA stands for Skilled Birth Attendance; ANC stands for Antenatal Care; JSY stands for Janani Suraksha Yojana (Mother Protection Scheme) 


\section{Table 3 (on next page)}

Crude and adjusted odds rati o s for neonatal death according to community characteristics and region of residence 
Table 3: Crude and adjusted odds ratios for neonatal death according to community characteristics and region of residence

\begin{tabular}{|c|c|c|c|c|c|c|c|c|}
\hline \multirow[t]{3}{*}{ Independent variables } & \multicolumn{4}{|c|}{ Unadjusted } & \multicolumn{4}{|c|}{ Adjusted $^{\odot}$} \\
\hline & \multirow[t]{2}{*}{ OR } & \multicolumn{2}{|c|}{ CI (95\%) } & \multirow[t]{2}{*}{ 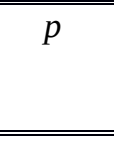 } & \multirow[t]{2}{*}{$\begin{array}{l}\text { OR } \\
\end{array}$} & \multicolumn{2}{|c|}{ CI (95\%) } & \multirow[t]{2}{*}{$\overline{p p}$} \\
\hline & & Lower & $\begin{array}{c}\text { Uppe } \\
\text { r } \\
\end{array}$ & & & Lower & Upper & \\
\hline \multicolumn{9}{|l|}{ Region } \\
\hline Central ${ }^{\circledR}$ & 1.00 & & & & 1.00 & & & \\
\hline North & 0.71 & 0.63 & 0.79 & $<0.001$ & 0.89 & 0.78 & 1.00 & $\begin{array}{c}0.05 \\
6\end{array}$ \\
\hline North-East & 0.72 & 0.66 & 0.80 & $<0.001$ & 0.64 & 0.53 & 0.77 & $\begin{array}{c}<0.0 \\
01\end{array}$ \\
\hline East & 0.46 & 0.40 & 0.53 & $<0.001$ & 0.69 & 0.62 & 0.76 & $\begin{array}{c}<0.0 \\
01\end{array}$ \\
\hline West & 0.42 & 0.35 & 0.50 & $<0.001$ & 0.51 & 0.42 & 0.62 & $\begin{array}{c}<0.0 \\
01\end{array}$ \\
\hline South & 0.57 & 0.49 & 0.65 & $<0.001$ & 0.73 & 0.62 & 0.86 & $\begin{array}{c}<0.0 \\
01\end{array}$ \\
\hline
\end{tabular}

\section{Community characteristics}

Accessibility by an all-weather road

$\begin{array}{ll}\text { No }{ }^{\circledR} & 1.00 \\ \text { Yes } & 1.04\end{array}$

Distance to nearest private health facility

Within $1 \mathrm{~km}{ }^{\circledR}$

1.00

1 to $5 \mathrm{kms}$

1.06

0.92

$1.22 \quad 0.409$

1.00

More than $5 \mathrm{~km}$

1.09

0.99

$1.21 \quad 0.074$

0.97

0.83

1.13

0.71

0.97

0.87

1.08

0.59

Distance to nearest government health facility Within $1 \mathrm{~km}{ }^{\circledR}$

1 to $5 \mathrm{kms}$

0.71

0.48

$1.05 \quad 0.084$

0.67

0.45

1.01

0.05

More than $5 \mathrm{~km}$

1.13

1.03

1.25

0.013

0.97

0.87

1.09

6

ANM/ASHA available in the village

$\mathrm{No} \circledast$

1.00

Yes

0.90

0.81

0.99

1.00

Janani Suraksha Yojana implemented

No ${ }^{\circledR}$

1.00

Yes

0.90

0.82

$0.99 \quad 0.034$

1.00

Proportion of mother's with secondary education

0.43

0.37

$0.49<0.001$

1.06

0.96

1.17

0.26

Proportion of rich households

0.49

0.43

$0.55<0.001$

0.87

0.70

1.09

0.22

9

0.04

Note: $p$ stands for p-value; CI (95\%) stands for Confidence Interval at 95\% level; OR stands for Odds Ratio; ANM/ASHA stands for Auxiliary Nurse and Midwife/Accredited Social Health Worker. (C) The logistic regression model controlled for following variables as well - mother's education, father's education, asset index, religion, caste/tribe, employment of the mother, improved source of water, improved toilet facility, house type, electricity, mother's age at birth, sex of the child, birth order of the child, timing and number of ANC visits, Tetanus Toxoid injection, Iron and Folic Acid tablets/syrup, delivery place and SBA, and delivery complications. 


\section{Table 4(on next page)}

Crude and adjusted odds ratios for neonatal death according to socioeconomic characteristics 
Table 4: Crude and adjusted odds ratio for neonatal death according to socioeconomic characteristics

\begin{tabular}{|c|c|c|c|c|c|c|c|c|}
\hline \multirow[t]{3}{*}{ Independent variables } & \multicolumn{4}{|c|}{ Unadjusted } & \multicolumn{4}{|c|}{ 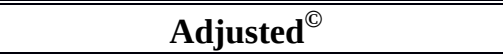 } \\
\hline & \multirow[t]{2}{*}{ OR } & \multicolumn{2}{|c|}{ CI (95\%) } & \multirow[t]{2}{*}{$p$} & \multirow[t]{2}{*}{ OR } & \multicolumn{2}{|c|}{ CI (95\%) } & \multirow[t]{2}{*}{$p$} \\
\hline & & Lower & Upper & & & Lower & Upper & \\
\hline \multicolumn{9}{|c|}{ Socioeconomic characteristics } \\
\hline \multicolumn{9}{|c|}{ Mother's education } \\
\hline Illiterate® & 1.00 & & & & 1.00 & & & \\
\hline Primary & 0.87 & 0.78 & 0.96 & 0.007 & 1.01 & 0.90 & 1.14 & 0.823 \\
\hline Secondary & 0.67 & 0.61 & 0.73 & $\begin{array}{c}<0.00 \\
1\end{array}$ & 0.96 & 0.85 & 1.09 & 0.563 \\
\hline > Secondary & 0.35 & 0.25 & 0.50 & $\begin{array}{c}<0.00 \\
1\end{array}$ & 0.60 & 0.41 & 0.88 & 0.009 \\
\hline \multicolumn{9}{|l|}{$\begin{array}{l}\text { Father's education } \\
\text { Illiterate }{ }^{\circledR}\end{array}$} \\
\hline Primary & 0.91 & 0.82 & 1.01 & 0.067 & 0.98 & 0.88 & 1.10 & 0.75 \\
\hline Secondary & 0.73 & 0.67 & 0.79 & $\begin{array}{c}<0.00 \\
1\end{array}$ & 0.85 & 0.76 & 0.94 & 0.00 \\
\hline > Secondary & 0.54 & 0.45 & 0.64 & $\begin{array}{c}<0.00 \\
1\end{array}$ & 0.76 & 0.61 & 0.94 & 0.01 \\
\hline \multicolumn{9}{|l|}{ Asset Index } \\
\hline Middle & 0.82 & 0.76 & 0.90 & $\begin{array}{c}<0.00 \\
1\end{array}$ & 1.00 & 0.91 & 1.10 & 0.967 \\
\hline Rich & 0.63 & 0.57 & 0.69 & $\begin{array}{c}<0.00 \\
1\end{array}$ & 1.04 & 0.90 & 1.19 & 0.612 \\
\hline \multicolumn{9}{|l|}{ Religion } \\
\hline Hindu ${ }^{\circledR}$ & 1.00 & & & & 1.00 & & & \\
\hline Muslim & 0.96 & 0.86 & 1.07 & 0.444 & 0.95 & 0.83 & 1.08 & 0.397 \\
\hline Others & 0.62 & 0.53 & 0.71 & $\begin{array}{c}<0.00 \\
1\end{array}$ & 0.99 & 0.83 & 1.17 & 0.881 \\
\hline \multicolumn{9}{|l|}{ Caste/Tribe } \\
\hline Scheduled Castes ${ }^{\circledR}$ & 1.00 & & & & 1.00 & & & \\
\hline Scheduled Tribes & 0.66 & 0.58 & 0.74 & $\begin{array}{c}<0.00 \\
1\end{array}$ & 0.72 & 0.63 & 0.82 & $<0.001$ \\
\hline Other Backward Castes & 0.92 & 0.83 & 1.01 & 0.066 & 0.94 & 0.85 & 1.04 & 0.207 \\
\hline General & 0.68 & 0.60 & 0.77 & $\begin{array}{c}<0.00 \\
1\end{array}$ & 0.87 & 0.77 & 0.99 & 0.041 \\
\hline \multicolumn{9}{|l|}{ Employment of the mother ${ }^{\Omega}$} \\
\hline $1{ }^{\circledR}$ & 1.00 & & & & 1.00 & & & \\
\hline 2 & 0.81 & 0.87 & 0.75 & 0.012 & 0.90 & 0.83 & 0.98 & 0.012 \\
\hline 3 & 0.81 & 0.95 & 0.68 & $\begin{array}{c}<0.00 \\
1\end{array}$ & 1.00 & 0.84 & 1.19 & 0.991 \\
\hline
\end{tabular}

Note: $p$ stands for p-value; CI (95\%) stands for Confidence Interval at $95 \%$ level; OR stands for Odds Ratio; ${ }^{\Omega}$ Employment of the mother: $1=$ Agricultural worker/farmer/labourer, 2 = Unemployed, 3 = Professional/service/production. (C) The logistic regression model controlled for following variables as well - region, accessibility by an all-weather road, distance to nearest private health facility, distance to nearest public health facility, ANM/ASHA available in the village, Janani Suraksha Yojana implemented, proportion of mother's with secondary education, proportion of rich households, improved source of water, improved toilet facility, house type, electricity, mother's age at birth, sex of the child, birth order of the child, timing and number of ANC visits, Tetanus Toxoid injection, Iron and Folic Acid tablets/syrup, delivery place and SBA, and delivery complications. 


\section{Table 5 (on next page)}

Crude and adjusted odds ratios for neonatal death according to household environmental factors 
Table 5: Crude and adjusted odds ratios for neonatal death according to household environmental factors

\begin{tabular}{|c|c|c|c|c|c|c|c|c|}
\hline \multirow[t]{3}{*}{ Independent variables } & \multicolumn{4}{|c|}{ Unadjusted } & \multicolumn{4}{|c|}{ Adjusted $^{\odot}$} \\
\hline & \multirow[t]{2}{*}{ OR } & \multicolumn{2}{|c|}{ CI (95\%) } & \multirow[t]{2}{*}{$p$} & \multirow[t]{2}{*}{ OR } & \multicolumn{2}{|c|}{ CI (95\%) } & \multirow[t]{2}{*}{$p$} \\
\hline & & Lower & Upper & & & Lower & Upper & \\
\hline \multicolumn{9}{|l|}{ Household environment } \\
\hline \multicolumn{9}{|l|}{ Improved source of water } \\
\hline No & 1.00 & & & & 1.00 & & & \\
\hline Yes & 1.30 & 1.20 & 1.41 & $\begin{array}{c}<0.00 \\
1\end{array}$ & 1.13 & 1.04 & 1.24 & 0.006 \\
\hline \multicolumn{9}{|l|}{ Improved toilet facility } \\
\hline No & 1.00 & & & & 1.00 & & & \\
\hline Yes & 0.59 & 0.54 & 0.65 & $\begin{array}{c}<0.00 \\
1\end{array}$ & 0.87 & 0.77 & 0.98 & 0.019 \\
\hline \multicolumn{9}{|l|}{ House type } \\
\hline Kachcha & 1.00 & & & & 1.00 & & & \\
\hline Pucca & 0.68 & 0.61 & 0.76 & $\begin{array}{c}<0.00 \\
1\end{array}$ & 0.87 & 0.77 & 0.98 & 0.025 \\
\hline \multicolumn{9}{|l|}{ Electricity } \\
\hline $\begin{array}{l}\text { No } \\
\text { Yes }\end{array}$ & $\begin{array}{l}1.00 \\
0.68\end{array}$ & & & $<0.00$ & $\begin{array}{l}1.00 \\
0.84\end{array}$ & & & \\
\hline Yes & 0.68 & 0.63 & 0.73 & 1 & 0.84 & $0 . / 6$ & 0.92 & $<0.001$ \\
\hline
\end{tabular}

Note: $p$ stands for p-value; CI (95\%) stands for Confidence Interval at 95\% level; OR stands for Odds Ratio. (C) The logistic regression model controlled for following variables as well - region, accessibility by an all-weather road, distance to nearest private health facility, distance to nearest public health facility, ANM/ASHA available in the village, Janani Suraksha Yojana implemented, proportion of mother's with secondary education, proportion of rich households, mother's education, father's education, asset index, religion, caste/tribe, employment of the mother, mother's age at birth, sex of the child, birth order of the child, timing and number of ANC visits, Tetanus Toxoid injection, Iron and Folic Acid tablets/syrup, delivery place and SBA, and delivery complications. 


\section{Table 6 (on next page)}

Crude and adjusted odds ratios for neonatal death according to proximate determinants 
Table 6: Crude and adjusted odds ratios for neonatal death according to proximate determinants

\begin{tabular}{|c|c|c|c|c|c|c|c|c|}
\hline \multirow[t]{3}{*}{ Independent variables } & \multicolumn{4}{|c|}{ Unadjusted } & \multicolumn{4}{|c|}{ Adjusted $^{\odot}$} \\
\hline & \multirow[t]{2}{*}{ OR } & \multicolumn{2}{|c|}{ CI (95\%) } & \multirow[t]{2}{*}{$p$} & \multirow[t]{2}{*}{ OR } & \multicolumn{2}{|c|}{ CI (95\%) } & $\bar{p}$ \\
\hline & & Lower & Upper & & & Lower & Upper & \\
\hline
\end{tabular}

\section{Proximate determinants}

Mother's age at birth

Below 20

20-24

25-29

30 and above

Sex of the child

Girl

Boys

Birth order of the child 1

2

3

4 and above

Timing and number of ANC visits

No ANC visits

First trimester $+>=4$ ANC visits

First trimester $+<4$ ANC visits

$2^{\text {nd }}$ or $3^{\text {rd }}$ semester ANC visits

Tetanus Toxoid injection

One

No

Two or more

Iron and Folic Acid tablets/syrup

No

Yes

Delivery place and SBA

Home

Home but SBA

Health facility

Delivery complications

No

Yes
1.00

0.68

0.56

0.70

1.00

1.20

1.12

1.00

0.65

0.62

0.58

0.56

0.80

0.73

1.00

0.64

0.80

0.57

0.71

0.89

0.72

0.82

1.00

0.88

0.67

1.00

0.99

1.00

0.88

1.06

0.75

0.98

1.05

1.14

0.176

1.00

1.29
1.02

0.77

0.77

0.083

$<0.00$

1

0.92

1.06

0.719

1.00

0.75

0.65

$0.87<0.001$

0.65

0.56

$0.75<0.001$

Note: $p$ stands for p-value; CI (95\%) stands for Confidence Interval at 95\% level; OR stands for Odds Ratio; SBA stands for Skilled Birth Attendance; ANC stands for Antenatal Care. (C) The logistic regression model controlled for following variables as well - region, accessibility by an all-weather road, distance to nearest private health facility, distance to nearest public health facility, ANM/ASHA available in the village, Janani Suraksha Yojana implemented, proportion of mother's with secondary education, proportion of rich households, mother's education, father's education, asset index, religion, caste/tribe, employment of the mother, improved source of water, improved toilet facility, house type, electricity. 


\section{Figure 1}

Conceptual framework showing factors affecting neonatal mortality

\section{Community} level factors

- distance to governement health facility

- distance to private health facility

- ANM/ASHA available in the village

- Janani Suraksha

Yojana (Safe motherhood programe) implemented in the village

- Proportion of mothers with secondry education in the village

- proportion of mothers belonging to rich households in the village

- connectivity of the village with allweather road

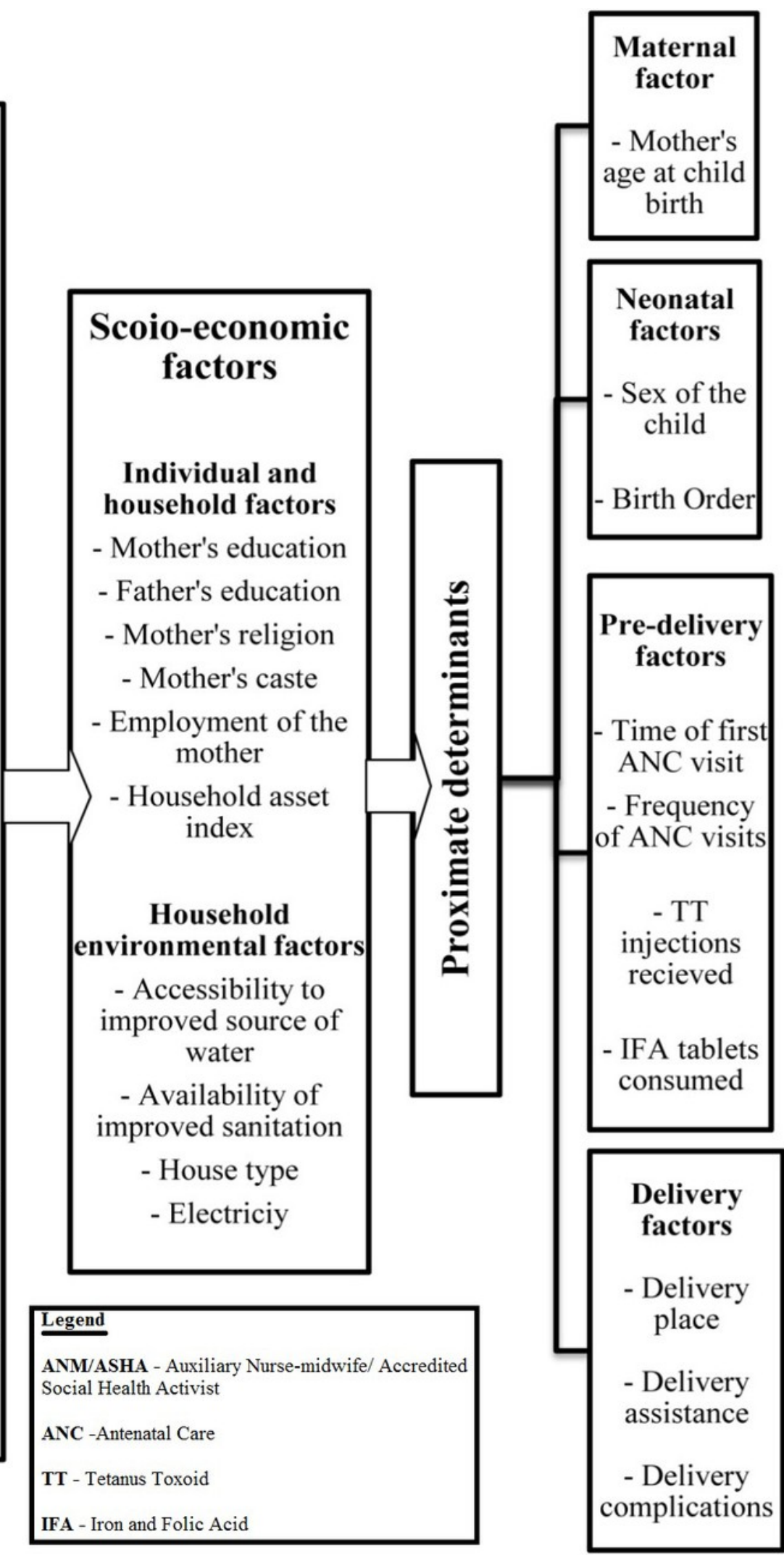

Death

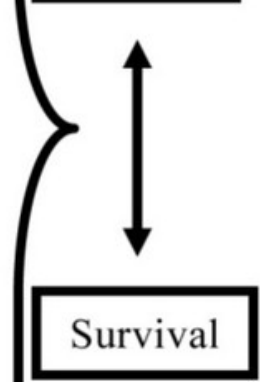

